\title{
First Infestation Case of Sarcoptic Mange from a Pet Rabbit Oryctolagus cuniculus in Republic of Korea
}

\author{
Seongjun Choe ${ }^{1} \oplus$, Sungryong Kim², Ki-Jeong Na ${ }^{2,3}$, Tilak Chandra Nath', Barakaeli Abdieli Ndosi ${ }^{1,4}$, Yeseul Kang ${ }^{1}$, \\ Mohammed Mebarek Bia', Dongmin Lee ${ }^{1}$, Hansol Park', Chatanun Eamudomkarn ${ }^{1,5}$, Hyeong-Kyu Jeon', \\ Keeseon S. Eom ${ }^{1, *}$ \\ 'Department of Parasitology, Parasite Research Center and Parasite Resource Bank, School of Medicine, Chungbuk National University, \\ Cheongju 28644, Korea; '2Department of Veterinary Medicine, Chungbuk National University, Cheongju 28644, Korea; ${ }^{3}$ Widllife Center of Chungbuk, \\ Cheongju 28116 Korea; ${ }^{T}$ Tanzania Widlife Management Authority, P.O. BOX 2658 Morogoro, Tanzania; ${ }^{5}$ Department of Parasitology, Faculty of \\ Medicine, Khon Kaen University, Khon Kaen, Thailand
}

\begin{abstract}
In November 2019 a 5-month-old mixed-breed rabbit presented to Chungbuk National University Veterinary Teaching Hospital, Cheongju-si, Chungbuk, Republic of Korea (Korea) with symptoms comprising pruritus, crusts on skin, poor appetite and reduced defecation. The rabbit was purchased 2 months prior from a pet shop located in a big market, and that the symptoms were first observed about 2 weeks prior to the hospital visit. Physical examination revealed that the patient had crust formation and alopecia on the nose together with lesions on the digits. A skin scraping test was performed using mineral oil and a high density of mites was observed by microscopy. Each mite showed a round, tortoiselike body with 4 comparatively short pairs of legs. The anus was located at the terminal unlike with suspected pathogen, Notoedres cati. Based on morphological characteristics, we identified the mite as Sarcoptes sp. Ivermectin was administered weekly by subcutaneous injection at a dosage of $0.4 \mathrm{mg} / \mathrm{kg}$, and 4 weeks of follow-up study revealed the patient was fully recovered. And no more mites were detected from the case. This is the first case report of sarcoptic mange in a pet rabbit in Korea.
\end{abstract}

Key words: Sarcoptic mange, rabbit, ivermectin

\section{INTRODUCTION}

Sarcoptic mange or scabies is a highly contagious skin disease caused by the mite species Sarcoptes scabiei (Linnaeus, 1758) Latreille, 1802 (Acaridida: Sarcoptidae). This mite infestation has been reported globally from at least 104 species of mammalian hosts including domestic and wild mammals, as well as in humans [1-3].

Sarcoptes scabiei is a burrowing mite, and spends most of its life-span in tunnels set under the host's skin, i.e., at the stratum granulosum of the epidermis [4]. When infection occurs, it usually presents with several signs such as seborrheic dermatitis, erythematous papules, hyperemia and partial alopecia at the beginning. The condition is also associated with crusting,

- Received 16 January 2020, revised 14 May 2020, accepted 1 June 2020.

*Corresponding author (kseom@chungbuk.ac.kr)

(c) 2020, Korean Society for Parasitology and Tropical Medicine

This is an Open Access article distributed under the terms of the Creative Commons Attribution Non-Commercial License (https://creativecommons.org/licenses/by-nc/4.0) which permits unrestricted non-commercial use, distribution, and reproduction in any

medium, provided the original work is properly cited. thickening of the skin, wrinkled, extensive hyperkeratosis, loss of hair, and even death at the chronic stage $[1,2,5]$. Human scabies show similar clinical signs, but if the mites originated from another animal host the infections are mostly self-limited and short-lived [1,2].

Infestation of ectoparasites in pet rabbits has been commonly observed by veterinary clinicians in the Republic of Korea (Korea). To date, several cases of ectoparasites including Cheyletiella parasitovorax (Mégnin, 1878), Leporacarus gibbus (Pagenstecher, 1861), Psoroptes cuniculi (Delafond, 1859) and a mesostigamata mite species, Ornithonyssus bacoti Hirst, 1913 have been reported [7-13]. However, the sarcoptic mange in pet rabbits in Korea has hitherto not been reported. The aim of the present study is to describe the first case of Sarcoptes sp. infestation from a pet rabbit, Oryctolagus cuniculus (Linnaeus, 1758) in Korea.

\section{CASE DESCRIPTION}

A mixed-breed rabbit presented to Chungbuk National Uni- 
versity Veterinary Teaching Hospital, Cheongju-si, Korea in November, 2019 with scratching, crusts on skin, poor appetite and reduced defecation. The 5-month-old male rabbit had a body weight of $0.9 \mathrm{~kg}$. When relaying the history of the patient, the pet owner mentioned that the patient was purchased 2 months prior from a pet shop located in a big market, and that the symptoms were first observed about 2 weeks prior to the hospital visit. Upon physical examination of the patient, crust formation and alopecia were observed on the nose together with lesions on the digits (Fig. 1A, D).

A skin scraping test using mineral oil was performed from left and right forelimb digit lesions for diagnosis. The scraped
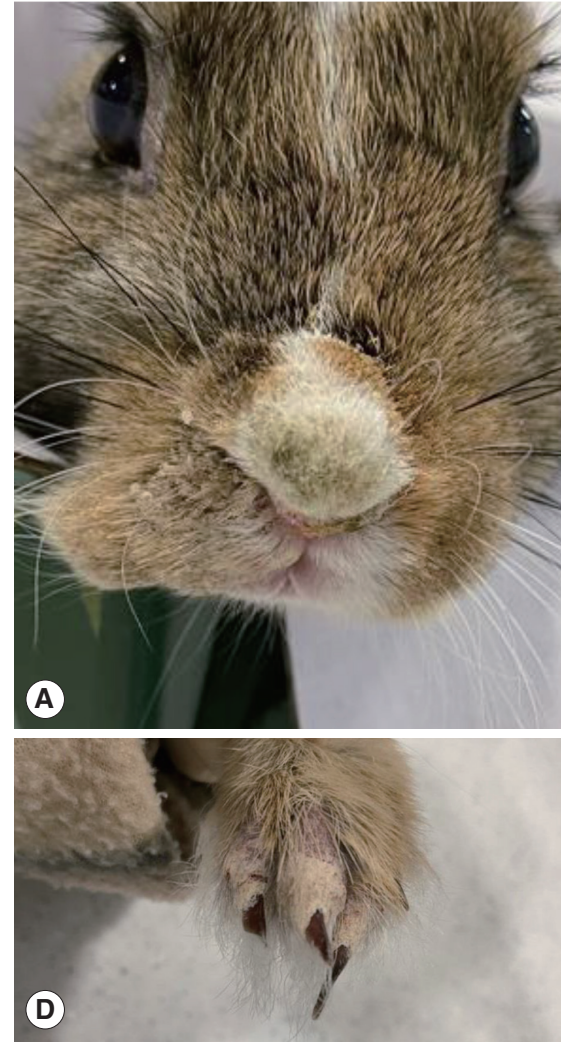
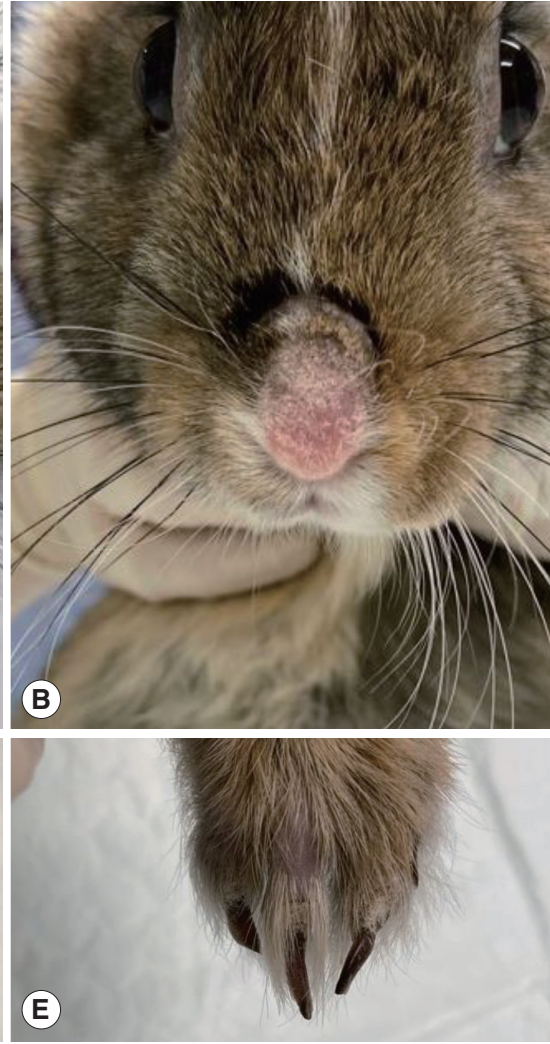
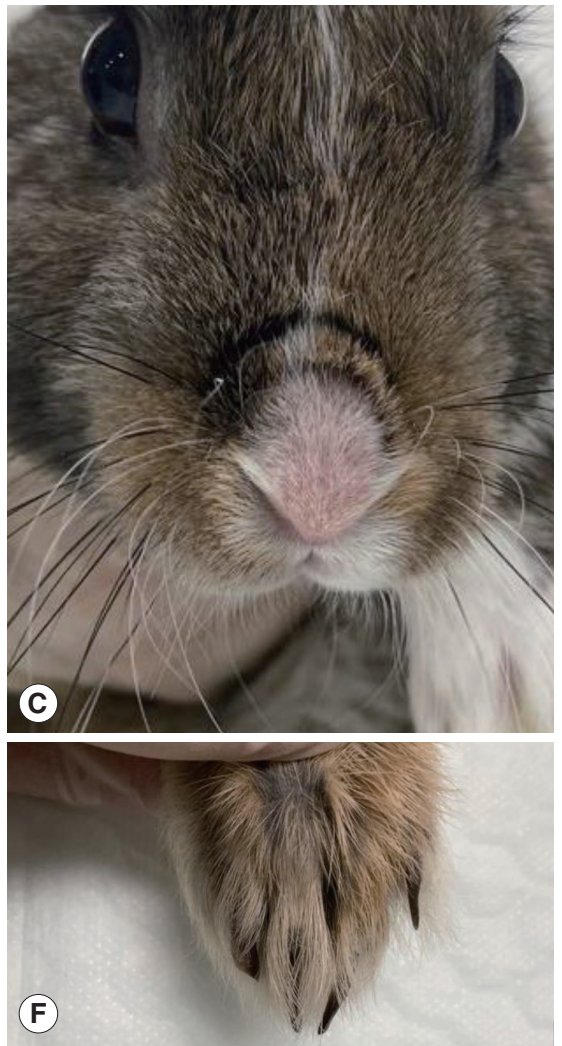

Fig. 1. Changes in gross lesions infected with Sarcoptes sp. in a pet rabbit over time. (A-C) Nose lesions. (D-F) Digit lesions. Pictures show lesions of crust formation on nose and digits on the first visit (A, D), and recovered one week (B, E) and 2 weeks later (C, F).
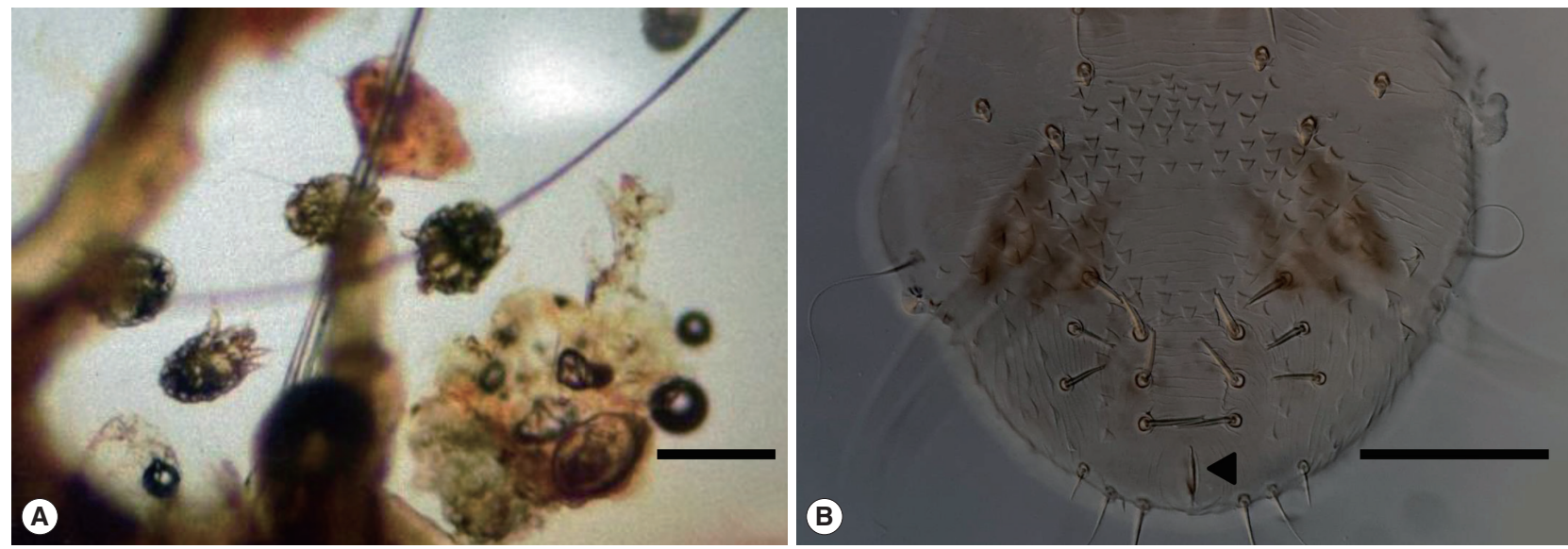

Fig. 2. Sarcoptes sp. recovered in the present study. (A) Scraping shows mites and crusts. (B) Dorsal side of Sarcoptes sp., showing triangular scales with bare lesions at the center. The anus is located at the terminal (arrow head). Scale bars $=500 \mu \mathrm{m}(\mathrm{A})$ and $100 \mu \mathrm{m}(\mathrm{B})$. 
crusts were observed under a light microscope after direct smear on slides. The microscopy revealed that the crusts contained a high density of mites comprising all developmental stages including egg, larva, nymphs and adult (Fig. 2A). Some of the mites were isolated using insect pins and pipettes and then preserved in 70\% ethyl alcohol for further study.

Adult mites were randomly chosen and immersed in lactic acid for 24 hours for maceration, and then mounted with polyvinyl alcohol for microscopic observation. From a morphological perspective, each mite showed a round, tortoiselike body with 4 comparatively short pairs of legs. In female mites, 2 pairs of legs extended forwards and were equipped with a long thin stalked empodium with a sucker on the tip, while the other 2 pairs extended backwards with elongated thin bristles at the tips. Unlike the female mites, male mites showed a stalked empodium with a sucker at the tip of the 4 pairs of legs in lieu of bristles. The sizes of the female and male mites were 360-423 × 270-315 $\mu \mathrm{m}$ and 240-284× 177-191 $\mu \mathrm{m}$, respectively. The dorsal side of the body was armed with triangular scales, and the anus was located at the terminal (Fig. 2B). Based on the keys to arthropod parasites, these morphological characteristics indicated that our specimens were belonging to genus Sarcoptes $[14,15]$.

For treatment, Ivermectin (Ivomec, Merial) was administered to the patient weekly by subcutaneous injection at a dose of $0.4 \mathrm{mg} / \mathrm{kg}$ during the course of one month. Follow-up studies were conducted and the patient was re-evaluated weekly after the treatment (Fig. 1). The weight of the rabbit was $0.9 \mathrm{~kg}$ on first visit and then increased to $1.1,1.15$, and $1.24 \mathrm{~kg}$ at the second to 4 th weeks of the treatment, respectively. Subsequent skin scraping tests revealed that no mites had survived at 4 weeks after the first visit.

\section{DISCUSSION}

In the present study we revealed the infestation of Sarcoptes mites in rabbit in K orea. Present specimens showed wellmatched morphological characteristics with the key characters of Sarcoptes and clinical signs previously documented $[2,3,5,16]$. This small mite species can be distinguished from other ectoparasites of rabbit reported in Korea by its morphology and habitat in the host (burrowing vs. non-burrowing). A mite species that shows similar morphological characteristics as Sarcoptes and clinical signs of infestation is Notoedres cati (Hering, 1838) Railliet, 1893. Differential diagnosis is possible as $N$. cati has its anus at the dorsal surface of the body, while the anus of Sarcoptes is located at the terminal as shown in the present study (Fig. 2B) [1,16]. Although clinical signs can be employed to identify possible scabies in animals, most ectoparasites in rabbits show similar clinical manifestations as scabies such as pruritus and scaling, hence proper sampling and morphological observations are needed for the accurate identification of pathogens. Additionally, this condition should be distinguished from other skin diseases which show similar clinical signs [3].

When relaying the history of the patient at the first hospital visit, the pet owner mentioned that the patient was purchased 2 months prior from a pet shop located in a big market. The rabbit had been raised indoors after being purchased, and only had the opportunity to roam free on the sand for few hours near a marine beach one month prior. Sarcoptic mange is generally considered to occur via direct or indirect transmission of mites from infected hosts [3]. Thus, we suspect that direct or indirect contact may have occurred between the patient and infected animals at the location where the rabbit was bred before being purchased by the owner. Infection may also have occurred at the owner's house via facilities, items and feeds contaminated with Sarcoptes sp., or indeed outside when the rabbit was exposed to the beach area. Considering that the life cycle takes 10 to 13 days from egg to the adult stage as revealed by systematic in vivo studies in rabbits [4], all of the aforementioned suspected routes contain sufficient time to complete the life cycle and to yield new generations. The high density of mites found, however, indicates that this infection may have occurred long ago. In many cases, a positive diagnosis of scabies is very difficult in the early stages of infection due to the small number of mites [3]. In our case, the owner became aware of the symptoms only 2 weeks prior to the first hospital visit (one and a half months after the rabbit had been purchased). Thomsett [17] has indicated that the condition may not be noticed when fur covers the lesion.

The extent of infestation of Sarcoptes sp. among pet rabbits bred in Korea remains unknown. Considering the opinions of local veterinary clinicians, it appears that dermatological problems related to ectoparasites seem to be common in pet rabbits in Korea. To date, only 4 species of ectoparasites, namely Cheyletiella parasitovorax, Leporacarus gibbus, Psoroptes cuniculi, and Ornithonyssus bacoti have been reported in the literature [713]. Although most of these studies comprised only a small number of infected rabbits, 2 reports detail investigation of a 
large number of rabbits with ectoparasite infestation in Korea. Kim et al. [8] investigated fur mites and the clinical signs of pruritus in 140 pet rabbits. Kim et al. [12] examined 251 pet rabbits in the Daejeon-si area and identified 3 ectoparasites. It is noteworthy that although these investigations dealt with a large number of rabbits, no mention was made of $S$. scabiei. Whether S. scabiei infestations did exist is unclear due to the absence of further reports. It seems clear, however, that the identification and recording of $S$. scabiei in rabbits were neglected in Korea, and further studies are needed.

Research pertaining to the classification of $S$. scabiei has yet to be completed. To date, S. scabiei is commonly classified in various ways depending on the host species. For example, $S$. scabiei infected in rabbits is regarded as $S$. scabiei var. cuniculi [18-22]. However, Arlian et al. [6] provided some experimental results on the cross transmission of $S$ scabiei between domestic rabbits and dogs. The experiments showed that $S$. scabiei recovered from infected dogs can infect rabbits and that the reverse infection was also possible. This means that, unlike the case of infection of humans by S. scabiei originating from animals $[1,4]$, cross-infection is possible and may share the same mite species [3,6]. Zhao et al. [23] suggested that Sarcoptes mites identified in humans from Australia, China and Panama actually comprises multiple species including at least 4 different species based on phylogenetic trees generated from a 317-bp mtDNA cox 1 sequence. Furthermore, Sarcoptes mites from 9 animal species (buffalo, rabbit, cattle, sheep, dog, wombat, wallaby, pig, and chimpanzee) cluster as a subbranch. Based on the results, they used the name for Sarcoptes mites from man and animals as $S$. hominis and S. canis, relatively [23]. Despite the various attempts, the classification of these species is still unclear $[2,3]$. Due to not enough volume of the specimen, we could not get DNA sequences and conduct the species identification. Thus, here we use the name as Sarcoptes sp., however, it is suspected that the mites in the present study are close to animal type of Sarcoptes. The owner mentioned that their child recently visited a dermatologist due to itching of the skin after touched the rabbit, and the symptoms recovered completely within a few weeks as like the scabies originated from other hosts $[1,2]$. Although it was not possible to directly confirm whether the skin problem was due to scabies, it should be concerend because the animal scabies have the potential to be infected to human.

Various kinds of drugs have been employed to control this mite infestation. The acaricidal drug Ivermectin is one such drug, and its effectiveness in treating sarcoptic mange in rabbits and other animals has been verified in multiple case studies $[1,2,5,15,24]$. Ivermectin was administered weekly by subcutaneous injection at a dose of $0.4 \mathrm{mg} / \mathrm{kg}$ over a 4 -week period. This approach was observed to be highly effective in the present case without any side effects. The patient quickly recovered its health and gained some weight after the treatment, as also observed by Nfi [24]. Improvements in maintaining hygiene of the breeding environment by the owner would also have helped in the promising prognosis.

In conclusion, we described a case of sarcoptic mange in a pet rabbit. We analyzed the morphology of the mite isolated from the rabbit, and revealed that the cause of clinical symptoms was Sarcoptes mite. Additionally, we successfully treated the mite infection using Ivermectin. However, since we only dealt with one case of sarcoptic mange in a pet rabbit that had been bred alone in an indoor environment, there is still limited information pertaining to the prevalence and epidemiology of mite infestation among pet rabbits in Korea. Further studies are therefore required to investigate this zoonotic parasite in terms of animal and human public health.

\section{CONFLICT OF INTEREST}

We have no conflict of interest related to this work.

\section{REFERRENCES}

1. Bornstein S, Mörner T, Samuel WM. Sarcoptes scabiei and sarcoptic mange. In Samuel WM, Pybus MJ, Kocan AA eds, Parasitic Diseases of Wild Mammals. 2nd ed. Ames, USA. Iowa State University Press. 2001, pp 107-119.

2. Pence DB, Ueckermann E. Sarcoptic mange in wildlife. Rev Sci Tech 2002; 21: 385-398.

3. Arlian LG, Morgan MS. A review of Sarcoptes scabiei: past, present and future. Parasit Vectors 2017; 10: 297.

4. Arlian LG, Vyszenski-Moher DL. Life cycle of Sarcoptes scabiei var. canis. J Parasitol 1988; 74: 427-430.

5. Baker DG. Flynn's Parasites of Laboratory Animals. 2nd ed. Ames, USA. Blackwell Publishing. 2007, pp 813.

6. Arlian LG, Runyan RA, Estes SA. Cross infestivity of Sarcoptes scabiei. J Am Acad Dermatol 1984; 10: 979-986.

7. Hoh WP, Oh HH, Eom KD, Lee KW, Oh TH. A case of naturally acquired cheyletiellosis in a rabbit: therapeutic trial of Selamectin. J Vet Clin 2005; 22: 56-59.

8. Kim SH, Jun HK, Song KH, Gram Dunbar, Kim DH. Prevalence of fur mites in pet rabbits in South Korea. Vet Dermatol 2008; 19: 189-190. 
9. Son HY, Kim SH, Kim DH, Kim NS, Kim HC, Woon JH, Cho JG, Park BK. A record of Ornithonyssus bacoti from pet rabbit (Lionhead rabbits, Oryctolagus cuniculus) in Korea. J Vet Clin 2009; 26: 600-602.

10. Kim SH, Choi KH, Kim DH. Use of a combination Imidacloprid and Permethrin for psoroptic mite infestation in three pet rabbits. J Vet Clin 2009; 26: 622-624.

11. Eo KY, Kwon OD. Psoroptic otocariasis associated with Psoroptes cuniculi in domestic rabbits in Korea. Pak Vet J 2010; 30: 251-252.

12. Kim SH, Kim S, Park HJ, Seo KW, Song KH. Ectoparasites infestation rates in the pet rabbits of Daejeon Area, Korea. J Vet Clin 2013; 30: 186-188.

13. Kim KT, Lee SH, Kwak DM. Ear mite infestation in a lop-eared rabbit (Oryctolagus cuniculus) and successful treatment with ivermectin. Korean J Vet Serv 38: 137-140.

14. Krantz GW, Walter DE. A Manual of Acarology. 3rd ed. Lubbock, USA. Texas Tech University Press. 2009, pp 807.

15. Bochkov AV. A review of mammal-associated Psoroptidia (Acariformes: Astigmata). Acarina 2010; 18: 99-260 (in Russian).

16. Timm KI. Pruritus in rabbits, rodents and ferrets. Vet Clin North Am Small Anim Pract 1988; 18: 1077-1091.

17. Thomsett LR. Mite infestations of man contracted from dogs and cats. Br Med J 1968; 3: 93-95.
18. Millán J. First description of sarcoptic mange in wild European rabbit (Oryctolagus cuniculus). Eur J Wildl Res 2010; 56: 455-457.

19. Arul Prakash M, Soundararajan C, Nagarajan K, Tensingh Gnanaraj P, Ramesh Saravanakumar V. Sarcoptic mange infestation in rabbits in an organized farm at Tamil Nadu. J Parasit Dis 2017; 41: 429-432.

20. Singathia R, Gupta SR, Yadav R, Sudan V, Lakhotia RL, Sharma RL. Concurrent Sarcoptic scabiei var. cuniculi and Microsporum gypseum infestation in rabbits. J Vet Parasitol 2013; 27: 22-24.

21. Hu Z, Chen Z, Yin Z, Jia R, Song X, Li L, Zou Y, Liang X, Li L, He C, Yin L, Lv C, Zhao L, Su G, Ye G, Shi F. In vitro acaricidal activity of 1,8-cineole against Sarcoptes scabiei var. cuniculi and regulating effects on enzyme activity. Parasitol Res 2015; 114: 2959-2967.

22. Muhammad SS, Muhammad AN, Asma K, Muhammad J, Muhammad KS. Sarcoptes scabiei (Acari: Sarcoptidae) infestation in rabbits (Oryctolagus cuniculus): a case study. Rev Colomb Entomol 2017; 43: 51-54.

23. Zhao YE, Cao ZG, Cheng J, Hu L, Ma JX, Yang YJ, Wang XP, Zeng JH, Wang TP. Population identification of Sarcoptes hominis and Sarcoptes canis in China using DNA sequences. Parasitol Res 2015; 114: 1001-1010.

24. Nfi AN. Ivomec, a treatment against rabbit mange. Rev Elev Med Vet Pays Trop 1992; 45: 39-41. 
